$\begin{gathered}\text { EPiC Series in Education Science } \\ \text { Volume 1, 2017, Pages 271-278 }\end{gathered}$
$\begin{aligned} & \text { AUBEA 2017: Australasian Universities Build- } \\ & \text { ing Education Association Conference 2017 }\end{aligned}$

\title{
Application of RFID in the Prefabricated Timber Industry
}

\author{
Perry Forsythe ${ }^{1}$ and Brad Carey ${ }^{2}$ \\ ${ }^{1}$ University of Technology Sydney, Australia \\ ${ }^{2}$ Curtin University, Australia \\ Perry.Forsythe@uts.edu.au, Brad.Carey@curtin.edu.au
}

\begin{abstract}
RFID (Radio Frequency Identification) has recently gained significant attention in various industries, whereby a common application of the technology is to gather and transmit real-time information related to inventory control and logistics. This paper develops the case for the use of RFID in the prefabricated timber industry by first examining its application in other industries. From there, the paper presents a framework for the adoption and testing of RFID within the prefabricated timber industry as a method to automate inventory control, logistics, and document control, while optimizing construction duration. The paper presents the methodology for field trials designed to determine potential for RFID applications in the prefabricated timber structure supply chain from raw material production to panel fabrication to shipping and onsite logistics and finally through to construction installation. The methodology will be tested in collaboration with industry partners and Forest and Wood Products Australia.
\end{abstract}

\section{Introduction}

Radio Frequency Identification (RFID) technologies, refer to the process of indexing information of physical objects and using radio frequencies to transfer information from the object to interested users. RFID is a form of technology that can be used to automate information systems and supply information using RFID tags (attached to physical objects) and RFID readers operated by users. RFID has recently gained significant traction in various industries, supply chains and logistical applications due to its ability add value and generate cost benefits. Industries that have seen applications of RFID that lead to cost benefits include: logistics and shipping (Ramanathan et al. 2014), retail (Loebbecke, 2005), medical (Chao et al. 2007), and mining (Mahmad et al. 2016).

The construction industry is notoriously slow when it comes to adopting new technologies. The Global Construction Survey 2016 (KPMG International, 2016) identified that conservatism, as it pertains to the adoption and experimentation with technology, remains the norm in the construction industry, with most firms being content to follow rather than lead. A significant contributing factor to 
this conservatism is that many senior executives are worried about their organizations' ability to integrate disparate technologies, along with the costs and the subsequent impact upon the bottom line (KPMG International, 2016). Thus, when examining the applicability of technologies such as RFID to the construction industry, it is important to establish the cost benefits. Annual turnover for the respondent companies ranged from less than \$US1 billion to more than US\$20 billion (KPMG International, 2016). Which would indicate that these firms were in a better place to experiment with technology, yet when it comes to technology innovation, just 8 percent of the respondent organisations fell into the "cutting-edge visionary" category, while 69 percent were considered either "followers" or "behind the curve (KPMG International, 2016)."

Because firms do not feel as though they have the margins that are necessary in order for them to take on the costs and risks associated with being early implementers of new technologies, it is especially important that professional groups and academic researchers collaborate with industry to identify the cost benefits of implementing new technologies. Because of this, Forest and Wood Products Australia, a not-for-profit company that provides integrated research and development services to the Australian wood products industry has assisted the authors and industry partners to undertake research into the potential for RFID to add value in the prefabricated timber construction industry. The initial stages of the research are reported in this paper.

\section{Radio Frequency Identification}

RFID tags attached to a physical object allow a read and write capacity whereby very small amounts of information about the object can be stored on the tag this can be changed by writing new information, such as updates concerning quality control inspection, delivery to a certain location, completion have a defined process and so on. RFID provides wireless communication between tags and readers, which facilitates real-time information management through automated identification processes that don't require the physical examination of items. Using RFID, product data is automatically transmitted by radio signals. The key component of RFID technology is the RFID tag (called a transponder), which is a minute computer chip with an inbuilt antenna. As a tag passes through a radio frequency field generated by a compatible reader, it transmits stored data to the reader, thereby giving details about the object to which the RFID tag is attached. The RFID reader can be a tablet or other device, which can also be connected to the cloud whereby additional information that is generated during a product's time in the supply chain can be accessed or saved. Figure 1 shows the configuration for an RFID system. RFID systems operate in 'free air', i.e. non-regulated frequencies of the wireless communications spectrum.

RFID has been used successfully in industries including the shipping and logistics, retail, medical, and mining industries in order to generate cost benefits. The broad spectrum of industries benefiting from the use of RFID is indicative of its adaptability to meeting various user needs, including those needs of the timber construction industry. By reviewing past successful applications, a methodology can be created to test RFID's applicability to timber construction industry and collect empirical data related to such an application. 


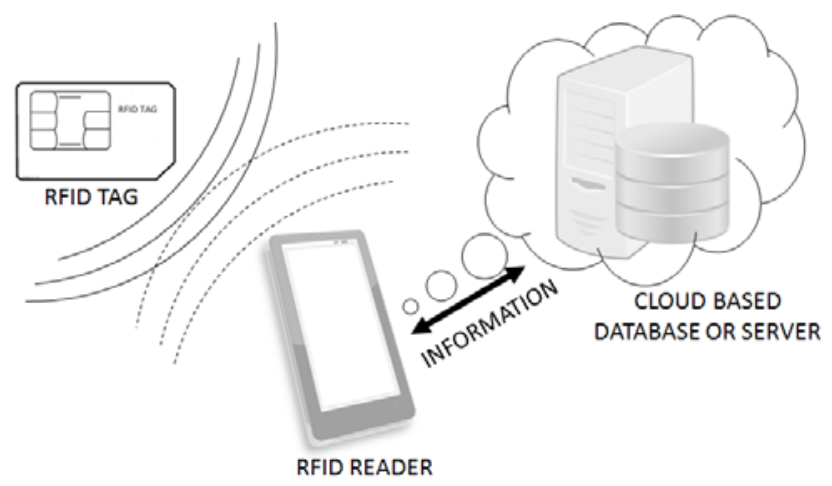

Figure 1: RFID Process

\subsection{RFID in Logistics and Shipping Industries}

In the logistics industry, RFID is used to check the integrity of products and determine if they have been tampered with during transit (Nagabhushana, 2013). RFID technology also serves to increase the flow of containers through shipping ports by speeding up container checking and administrative processes such as paper work. Manual checking of paperwork and filing becomes unnecessary, for the process is automated. RFID is also being used to check specific product parameters (temperature, pressure, and humidity) and to detect the chemical and biological substances within a shipping container (Nagabhushana, 2013).

Lee and Chan (2009) identified that RFID is being used in Reverse Logistics Systems, which assists in situations where customers return products for reuse or recycling. RFID tags can store model numbers and serial numbers of the products, manufacture dates, material information, and names of the retailers and distributors (Lee \& Chan, 2009), all of which can be used to assist in the recycling of materials at the end of a product's useful lifecycle.

\subsection{RFID in Retail}

In the retail supply chain, manufacturers attach time stamped RFID tags to all products, which are then entered into the central computer of the goods tracking system which will allow both the retailer and manufacturer to track and locate the tagged pallet along the logistic supply chain (Loebbecke 2005). RFID tags have also been used in receiving operations in warehouses. According to Gaukler and Seifert (2007), in a conventional non-RFID process, when receiving a pallet of goods, individual products in the pallet need to have bar codes scanned in order to be entered into the computer system to check the delivered products against orders. For that, a staff member needs to break into the pallet and scan each product. This is both time-consuming and mistake-prone. This scenario can be simplified if the products in the pallet were fitted with RFID tags, then entire pallets simply need to be pulled within range of the RFID reader portal, and from there all products in the pallet would be entered into the retail inventory management system instantaneously. Because of its success in creating cost benefits, the retail sector is currently undertaking the standardisation of RFID through the International Organisation for Standardization (Loebbecke 2005). 


\subsection{RFID in the Construction Industry}

According to Razavi and Haas (2011), deficiencies in material management are a common factor hampering construction productivity. These deficiencies may result from lost or damaged materials, unnecessary multiple handlings of materials, required materials not being procured, materials being procured but not received, and out of sequence material deliveries. Elghamrawy and Boukamp (2010) suggest, construction industry is a labour intensive industry with low levels of information integration. Those low levels of information integration could be improved with the use of RFID for materials and tool tracking (Sardroud 2012), document management (Elghamrawy \& Boukamp 2010), and providing real-time information. Jaselskis et al. (1995) as cited in Lu et al. (2011).

Hinkka and Tatila (2013) suggest the application of RFID technology in material management applications is easy and simple to adapt. If materials are tagged by the RFID system, then the material tracking management system will provide information about the progress of construction onsite, and materials delivered, by simply walking a site with an RFID reader in-hand. This would give more precise estimates of percentages of work completed and the quantity and quality of delivered goods (Lee et al. 2013).

Song et al. (2006) provide an example using RFID to track materials, wherein scans are performed on a concrete truck from a distance as it passes through a RFID gate to track materials. In addition, the technology has been adapted to automatically track delivery and receipt of prefabricated goods as they are dispatched and received through the entry gates on construction sites. According to Lee et al. (2013), an RFID system can create automatic billing upon receipt of materials at job-sites. Demiralp et al. (2012) did a case study and collected data by interviewing practitioners from precast concrete and construction companies and then running simulations on the use of RFID within the supply chain. Based on the simulations Demiralp et al. (2012) calculated cost savings of approximately 3\% on projects where prefabricated exterior concrete panels were fitted with RFID tags prior to entering the supply chain. Cost savings in the RFID cases were observed due to: (1) the reduced number of missing panels, and thus the reduced number of remanufactured panels; (2) the reduced number of incorrectly delivered/identified panels, and therefore, the decreased number of transfers; and (3) the reduced durations of some activities, resulting in decreased labour costs (Demiralp et al, 2012).

What can be gleaned from application in both construction and other industries is that the importance of logistics increases as the nature of prefabricated construction causes an inherent change in production processes from manually assembling many small objects onsite, to handling a smaller number of large and value added prefabricated objects, where care is needed in ensuring an efficient work flow from factory to site assembly. Concerning this:

- $\quad$ RFID can track large prefabricated objects with graduated checking of processes that span factory processing, factory storage, delivery logistics, installation sequencing, insitu placement and quantification of work complete for progress and billing.

- $\quad$ RFID can read through multiple layers of construction thus allowing retrospective checking of objects encapsulated within the construction. If used in conjunction with a holistic quality assurance system compliant with ISO 9000 (International Organization for Standardization [ISO], 2015), there is potential for it to be used as part of an information gathering, inspection and compliance regimes for prefabricated construction elements installed onsite. 


\section{Application of RFID to the Prefabricated Construction Industry}

After reviewing the literature related to the use of RFID in order to achieve cost savings, the authors have identified that the prefabricated timber industry could benefit from the implementation of RFID in the supply chain to track the manufacture, delivery, and installation of large prefabricated timber panels such as floor/roof cassettes or large Cross Laminated Timber (CLT) panels, which are becoming increasingly common as part of prefabricated construction solutions. The authors propose the following:

- Stages of timber panel fabrication can be monitored using RFID and provide accurate tracking of fabrication duration stage completion and that the use of RFID tags on completed panels will assist with sorting and crosschecking panels within the warehouse.

- $\quad$ RFID can draw panel identification information from BIM to factory production files that convert the architectural model to a panelised model of the building.

- For international or long distance shipping, geographic locating of freight can provide construction teams with notification of shipment.

- Using prefabricated panels will significantly reduce construction time and consequently costs, and that this can be accurately controlled using RFID to ensure the correct deliveries are being accepted on site.

- Usage of RFID tags and readers to verify correct sorting of panels in a given shipment for onsite storage and installation, thus reducing the time materials spend in storage onsite.

- Placement of RFID tags embedded inside or on timber panel does not significantly detract from performance of the RFID read through material (main construction materials are CLT and gyprock, and as such low levels of RFID interference are expected).

- $\quad$ RFID can be used in a Reverse Logistics System at the end of a building's lifecycle in order to ensure the correct material handling instructions are available to assist in disassembly and the sorting of products for reuse or recycling.

\subsection{RFID Testing and Research Design}

The authors aim to assess the following 7 aims by employing RFID in the construction supply chain on an active prefabricated timber construction project where the objective will be to:

1. Assess whether RFID can be used to measure time and resource utilisation, and track the fabrication stage of panels in factory (complements in place Enterprise Resource Planning systems (ERP)),

2. Assess whether RFID can be used at the factory to more efficiently stack the panels in order of construction site assembly in a shipping container,

3. Assess whether RFID can be used to automate the notification of construction teams that panel shipments are en route to site,

4. Assess whether RFID can be used by the construction team to access the location of shipping container, and obtain an accurate estimated time of arrival to the construction site,

5. Assess whether RFID be used by the construction team to verify that all panels are present and in the correct order in a shipment, as per the order, without physically unpacking or inspecting the container. This will be tested by linking panel RFID to a CAD/BIM model for assembly location (ie. panel B1-1 goes to this face of the building),

6. Assess whether RFID can allow for basic data storage on a tag attached to a given panel concerning basic physical properties (engineering material characteristics, material composition, thermal properties, sustainability properties, SDS) or in a linked online database (to allow for safety and sustainability compliance verification), 
7. Assess whether the placement of RFID tags embedded inside or on timber panels will detract from performance of the RFID reader once the panels has been covered by finishing materials such as plasterboard linings.

In order to measure time and resource utilisation, and track productivity in the fabrication stage of panel production in the factory, RFID tags will be fitted to prefabricated timber panels at the start of the manufacturing process in an area that will protect the RFID tag from damage during assembly. Information relating assembly design and material information and handling will be recorded on the RFID tag prior to being fitted on the panel. At the end of the manufacturing process the RFID tag will be read and the information related to manufacturing time and materials will be recorded to the tag and to the ERP system as well. Time comparisons between the traditional method of manual tracking and data entry will be compared with the automated RFID process. This approach is similar the approach identified by Loebbecke (2005) and Nagabhushana (2013) in the retail industry whereby RFID tags are attached at the point of manufacture and used to track items throughout the supply chain.

In order to assess if RFID can be used at the factory to more efficiently stack the panels in order of construction site assembly in a shipping container, the storage and handling team at the warehouse will use RFID readers to quickly and accurately verify panel identity prior to storage within the warehouse. In order to reduce unnecessary multiple handlings of materials in the warehouse and onsite like those identified by Razavi and Haas (2011), the panels can be stacked according to their shipping date, which will be quickly identifiable using the RFID reader. RFID tags can be used in quality control when loading panels into shipping container by scanning panels to review onsite installation order to ensure that the panels are loaded in the correct order. Thus creating a reduction in onsite material handling by the construction team because the panels come out of the container in the correct installation order.

In order to assess if RFID can be used to automate the notification of the construction team that a panel shipment is en route, an automated email will be generated when the shipping container is sealed and loaded for transport. The information related to shipping container contents, departure time, mode of transport, and estimated time of arrival, and a link to the GPS tracking will all be included in the email transmission.

In order to assess if RFID can be used by the construction team to access the location of shipping container and the estimated time of arrival to the construction site, the RFID tag on the shipping container will be augmented to allow for tracking using a standard GPS system. Just as was noted by Loebbecke (2005) when chronicling the retail industry, RFID tags will be electronically time stamped and then entered into the central computer of the goods tracking system which will allow both the panel manufacturer and contractor to track and locate the panels and shipping containers all along the logistic supply chain.

In order to assess if RFID can be used by the construction team to verify that all panels in the container are present as per the invoice and the panels are stacked in the order of building assembly, the construction team will use an RFID reader at the point of delivery to access the information related to the panels in the shipping container. Similar to logistics example noted by Nagabhushana (2013) the RFID reader will be used to determine the contents of the shipping container and each panel's individual identification and position within the container. The order of panels in the container will be checked against the construction plans using the cloud capabilities of the reader to view the CAD or BIM model.

In order to assess whether RFID can allow for the storage of panel physical properties (engineering material characteristics, material composition, thermal properties, sustainability properties, SDS) in the RFID Tag or in linked files in an online database (to allow for safety and sustainability compliance verification), the investigation will test two different approaches. The first approach will be to store the panel physical properties on the RFID tag itself to allow for quick access of the information via the RFID reader. The second approach will be store the panel physical properties in the CAD/BIM model and associate the properties with the RFID tag's identification number so that it can be accessed via the reader from the cloud after scanning the RFID tag. As was noted in Lee et al (2013) walking the 
construction site with an RFID reader in hand can be used to get precise information related to the panel's physical characteristics, the delivery times, and installation times. Furthermore, simulations will be done post construction to determine RFID can be used as Lee and Chan (2009) envisioned in Reverse Logistics Systems to assist in the identification of materials for recycling after the buildings useful lifecycle is complete.

In order to assess whether the placement of RFID tag embedded inside or on timber panel will detract from performance of the RFID reader once the panel has been covered by finishing materials like Cross Laminated Timber panels and gyprock, the researchers will test the readers and tags after the building has been occupied. This will allow for empirical testing to determine what impact different finish materials on the transmission of information from the tag to the reader.

In testing of RFID in the above mentioned ways, an RFID enabled prefabricated timber construction supply chain can be compared to a traditional prefabricated timber supply chain. Cost comparisons between the two paradigms can be compared and any potential cost benefits of RFID can be identified

\section{Conclusion}

Due to the thin profit margins experienced by firms in the construction industry, most firms are content to take a conservative approach when it comes to the implementation of new technologies. This conservatism has created the need for industry groups and academic to team up in order to test new technologies and identify any cost benefits to using technologies such as RFID in the construction supply chain.

The authors hypothesize that the implementation of RFID within the prefabricated timber supply chain will create cost savings in the form of a reduction in cost associated with the manufacture, storage, shipping and receiving, and on-site installation of prefabricated panels. The authors present a methodology for the empirical testing of RFID as a medium of information transfer and documentation, and intend to undertake tests that will examine the applicability of RFID with the prefabricated timber construction industry.

\section{Acknowledgements}

The authors would like to thank Forest and Wood Products Australia for their on-going financial support of the research presented in this paper.

\section{References}

Chao, C.C., Yang, J.M. and Jen, W.Y., (2007). Determining technology trends and forecasts of RFID by a historical review and bibliometric analysis from 1991 to 2005. Technovation, vol. 27, no. 5, pp.268-279

Demiralp, G, Guven, G, Ergen, E., (2012). Analysing the benefits of RFID technology for cost sharing in construction supply chains: A case study on prefabricated precast components, Automation in Construction, vol. 24, pp. 120-19. 
Elghamrawy, T and Boukamp, F, (2010). Managing construction information using RFID-based semantic contexts. Automation in Construction, vol. 19, no. 8, pp.1056-1066.

Gaukler, G.M and Seifert, R.W, (2007) Applications of RFID in supply chains. Trends in Supply Chain Design and Management, pp. 29-48.

Hinkka, V and Tatila, J, (2013). RFID tracking implementation model for the technical trade and construction supply chains. Automation in Construction, vol. 35, pp.405-414.

International Organization for Standardization. (2015). Quality Management Systems Fundamentals and Vocabularly. Retrieved from https://www-saiglobalcom.dbgw.lis.curtin.edu.au/online/autologin.asp

KPMG International (2016). Global Construction Survey 2016. [online] KPMG International. Available at: https://assets.kpmg.com/content/dam/kpmg/xx/pdf/2016/09/global-construction-survey2016.pdf [Accessed 21 Apr. 2017].

Lee, C.K.M and Chan, T. M. (2009). Development of RFID-based reverse logistics system. Expert Systems with Applications, vol. 36, no. 5, pp. 9299-9307.

Loebbecke, C., (2005). RFID technology and applications in the retail supply chain: The early Metro Group pilot. BLED 2005 Proceedings, p.42.

Lee, C.K.M and Chan, T. M. (2009). Development of RFID-based reverse logistics system. Expert Systems with Applications, vol. 36, no. 5, pp. 9299-9307.

Lee, J.H, Song, J.H., Oh, K.S. and Gu. N 2013, Information lifecycle management with RFID for material control on construction sites. Advanced Engineering Information, vol. 27, no. 1, pp. 108-119.

Lu, W, Huang, G. Q and Li, H (2011). Scenarios for applying RFID technology in construction project management. Automation in Construction, vol. 20, no. 2, pp. 101-106.

Mahmad, M.K.N., Rozainy, M.R., Zainol, M.A. and Baharum, N., (2016) Application of Radio Frequency Identification (RFID) in Mining Industries. IOP Conf. Series: Materials Science and Engineering 133012050 doi:10.1088/1757-899X/133/1/012050

Nagabhushana, P (2013). Design and Construction of an RFID-enabled Infrastructure: The Next Avatar of the Internet, Industrial and Systems Engineering series. CRC Press.

Ramanathan, R, Ramanathan,U, Larraine Ko, Lok Wan (2014). Adoption of RFID technologies in UK logistics: Moderating roles of size, barcode experience and government support. Expert Systems With Applications, vol. 41, no. 1, pp. 230-236.

Razavi, S.N. and Haas, C.T., (2011). Using reference RFID tags for calibrating the estimated locations of construction materials. Automation in Construction, vol. 20, no. 6, pp.677-685.

Sardroud, J.M., (2012). Influence of RFID technology on automated management of construction materials and components. Scientia Iranica, vol. 19, no. 3, pp.381-392.

Song, J, Haas, C.T. and Caldas, C.H (2006) Tracking the location of materials on construction job sites. Journal of Construction Engineering and Management, vol. 132, no. 9, pp. 911-918. 